\title{
Knowledge and practices of physicians on blood component therapy: a cross-sectional study from two tertiary hospitals in Nigeria
}

\author{
Esther Obi ${ }^{1}$, Claudius Diette-spiff ${ }^{1}$, Hannah Omunakwe ${ }^{2}$
}

1. Federal Medical Centre, Yenagoa, Haematology and Blood Transfusion.

2. Rivers State University Teaching Hospital, Dept of Pathology.

\begin{abstract}
Introduction: Comprehension of blood component therapy (BCT) has profound impact on transfusion outcomes. Variations from the standards in practices of BCT may jeopardize patient care.

Aim: To assess the understanding and implementation of BCT by physicians.

Methods: The study was carried out at two tertiary health care centres. It was a descriptive cross- sectional study using a self-administered, questionnaire comprising of 30 questions.

Result: A total of 265 physicians responded from various clinical specialties. Physicians studied showed remarkable knowledge $(98 \%)$ of BCT. Nevertheless, $92.8 \%$ of the respondents' were inclined to prescribing whole blood and the commonest reason given was ready availability at the blood bank. More than half of the respondents' have prescribed BCT with sedimented red cells and platelet concentrates being the most frequently prescribed blood components. Non-availability of blood components and cost implications were some of the identified limitations to the use of BCT.

Conclusion: Majority of the physicians have a good knowledge concerning BCT. Nonetheless, there was a knowledge-practice mismatch attributable to the unavailability of the various blood components limiting optimal practice of BCT. Strategies should be formulated to overcome these identified challenges to ensure quality transfusion services in our healthcare facilities.

Keywords: Physicians; blood component therapy; blood transfusion; blood components; knowledge.

DOI: https://dx.doi.org/10.4314/ahs.v21i3.32

Cite as: Obi E, Diette-spiff C, Omunakwe H. Knowledge and practices of physicians on blood component therapy: a cross-sectional study from two tertiary hospitals in Nigeria. Afri Health Sci. 2021;21(3). 1230-1236. bttps:// dx.doiorg/10.4314/abs.v21i3.32
\end{abstract}

\section{Background}

Blood transfusion is a very important and life-saving treatment, and a crucial component of contemporary health care. Physicians' knowledge about blood components and their demands, doses and administration, may have profound impact on patient care and outcome. Blood component therapy (BCT) is the therapeutic use of blood components rather than whole blood to treat a specific deficiency, avoid volume overload and minimize reactions to blood products that are not needed1. Blood components includes red cell concentrates (RCCs), fresh frozen plasma (FFP), platelet concentrates (PCs) and cryoprecipitate ${ }^{1}$.

Commonly, RCCs and other blood components are obtained by centrifugation methods with programmable

\section{Corresponding author: \\ Esther Obi, \\ Federal Medical Centre, \\ Yenagoa, Haematology and Blood Transfusion. \\ Email: drs.rehtse@gmail.com}

centrifuges and blood components separators (automatic or not) after whole blood collection, or through apheresis process ${ }^{2}$. In Sub-Saharan African, donor collection by apheresis and component separation using centrifugation methods are often out of reach. Transfusion services in those jurisdictions have neither the financial resources nor the technical capacities to implement these processes. Limited financial resources, shortage of trained staff and the poor electrification of these settings are the main constraints. Red cell concentrates are prepared by simple gravity, sedimentation in most of these countries including Nigeria ${ }^{3}$.

Most transfusion decisions are made by physicians with exposure in transfusion medicine from only undergraduate medical courses only and this knowledge has been observed in studies to be insufficient ${ }^{4}$. Majority of blood banking training barring transfusion medicine post graduate programme, is given in pathology residency programs. Unfortunately, these specialists are not always the bedside providers of blood transfusion ${ }^{5}$.

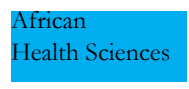

(C) 2021 Obi E et al. Licensee African Health Sciences. This is an Open Access article distributed under the terms of the Creative commons Attribution License (https://creativecommons.org/licenses/BY/4.0), which permits unrestricted use, distribution, and reproduction in any medium, provided the original work is properly cited. 
Physicians are required to have a basic knowledge of transfusion medicine to prescribe the right components for the right indications and practise its appropriate use ${ }^{6}$.

In most developing countries like Nigeria, the demand for blood far outweighs the supply ${ }^{7,8}$. There is thus, a need to optimise the use of blood component therapy by highlighting that one donation can be used for three transfusions. Therefore, adequate knowledge of blood component therapy by physicians may aid with the problems related to blood shortage and improve the quality management of patients who require blood transfusion.

The aim of this study was to assess the understanding and implementation of blood component therapy amongst physicians practising at two tertiary hospitals in Nigeria. There are limited studies assessing the knowledge and practice of blood component therapy among physicians in Nigeria. The findings of this study may be used to address the shortcomings in blood component therapy through continuing medical education and training to improve the quality of care of patients.

\section{Methods}

This was a descriptive cross-sectional survey using a self-administered questionnaire. A total of 265 physicians participated in this study.

This study was conducted in two tertiary care centers (University of Port Harcourt Teaching Hospital, Rivers State and Federal Medical Centre Yenagoa, Bayelsa State) within the South-South geopolitical zones of Nigeria. Nigeria is divided into six geopolitical zones (North-Central, North-East, North-West, South East, South-South and South-West) inclusive of states with similar ethnic groups and political history. States in the South-South zone are: Akwa-Ibom, Bayelsa, Rivers, Delta and Edo. The blood banks in these healthcare institutions provide blood services to all specialty and super-speciality wards.

The study was approved by the Federal Medical Centre, Yenagoa ethics committee and informed consent forms were signed by all participants.

Inclusion criteria were physicians from those specialities, where blood transfusion events are common like obstetrics and gynaecology, surgery, medicine, anaesthesia and paediatrics. Exclusion criteria includes: house Officers who have not completed at least two clinical rotations of approximately 24 weeks; physicians who were not actively working in clinical departments.; physicians from pathology who receive transfusion medicine training as their curriculum and who would have responded significantly better than others.

The questions were set by experienced transfusion medicine specialists at the Haematology department and reviewed by specialists of other departments for its content and clarity. A pilot test of the questionnaire was undertaken in hospital using a random sample of physicians from another tertiary hospital not under study who responded that the items were clear, important and understandable.

The survey consisted of 30 questions which were designed to address physicians' knowledge and clinical use of blood components including the limitations observed in the course of their practice. The questionnaire was offered to as many physicians as possible in the above mentioned departments without disturbing the routine. Survey was conducted only once in every department. All participants from one department were assessed simultaneously. Questionnaires was collected immediately after completion. Whole survey in all the above mentioned departments was conducted in three days in no particular order. Multiple-choice questions were used in this study to avoid the problems associated with scoring open-ended responses. The maximum possible score for the individual was 30 as each correct response was awarded one point. Some of the multiple choice questions had multiple answers. Each correct response was awarded one point, for questions with multiple answers, each option was also awarded one point respectively. A participant who gets all the options in a question wth multiple answers is awarded a full one point.

The data was presented using descriptive statistics (frequency and percentages). Chi-square analysis was used to assess the differences in the distributions of the variables. All analysis was done with the SPSS v25 software (IBM, USA) at a 95\% confidence interval and a p-value of 0.05 was considered significant.

\section{Results}

A total of 265 physicians participated in this study - out of which $192(72.1 \%)$ were residents, and 9 (3.4\%) were consultants. Majority of the participants were within the age range of $31-40$ years (table 1 ).

Internal medicine physicians were the highest proportion of respondents from the 168 participants who indicated their field of specialty as seen in figure 1. 
Table 1: Demographic Distribution of Respondents

\begin{tabular}{llll}
\hline & Age Groups & $\begin{array}{l}\text { Frequency } \\
(\mathbf{n = 2 6 5})\end{array}$ & Percent \\
\hline \multirow{2}{*}{ Age Groups } & 20-30 years & 41 & $15.5 \%$ \\
& 31-40 years & 161 & $60.8 \%$ \\
& $51-60$ years & 55 & $20.6 \%$ \\
& 41-50 years & 8 & $3.1 \%$ \\
\hline Gender & Female & 117 & $44.3 \%$ \\
& Male & 148 & $55.7 \%$ \\
\hline \multirow{2}{*}{ Designation } & Consultant & 9 & $3.4 \%$ \\
& Medical officer & 7 & $2.6 \%$ \\
& & & $21.1 \%$ \\
Years & Resident & 192 & $72.5 \%$ \\
Practice & Other & 1 & $0.4 \%$ \\
& & & \\
& <1 year & 39 & $14.4 \%$ \\
& 1-5 years & 90 & $34.0 \%$ \\
& 5-10 years & 68 & $25.8 \%$ \\
& Above 10 years & 68 & $25.8 \%$ \\
\hline
\end{tabular}

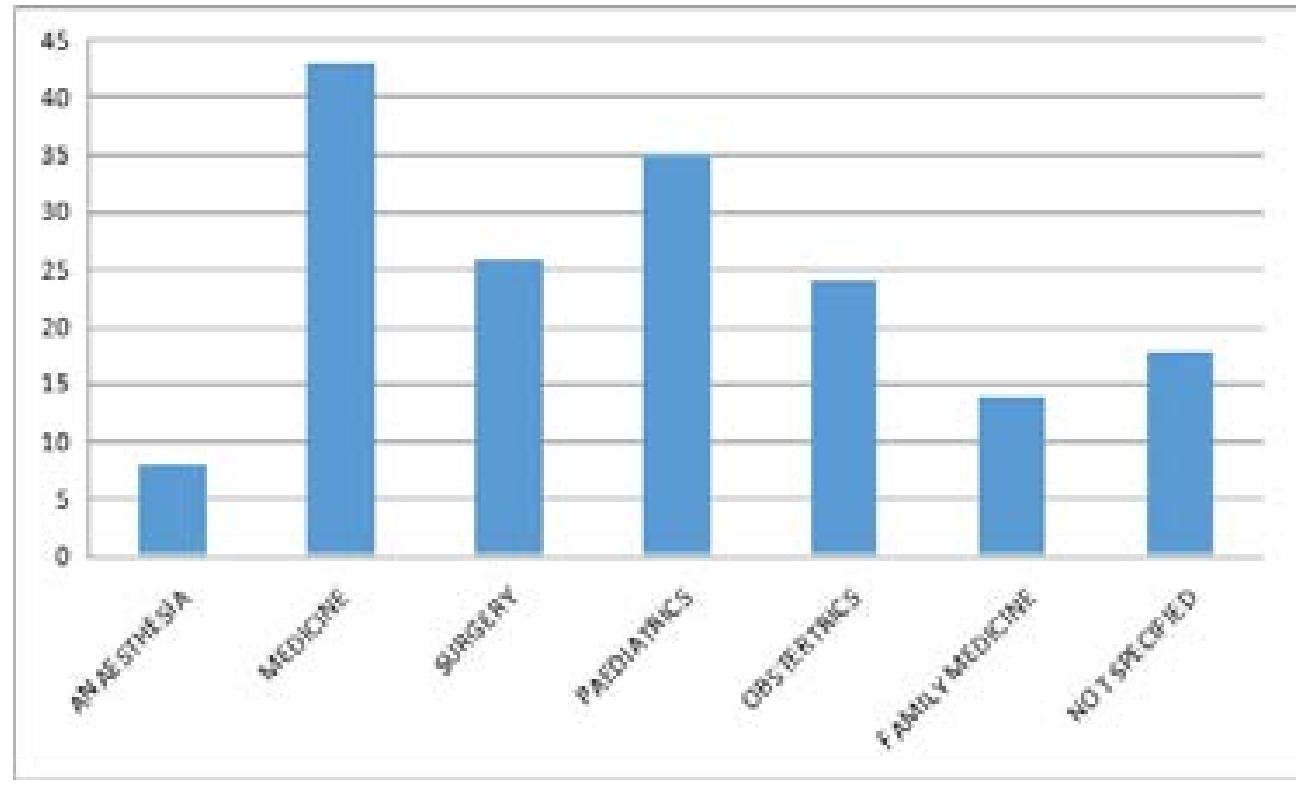

\section{Knowledge of Blood Components}

Ninety-eight percent of respondents indicated they had heard about BCT. The two major sources of information were from undergraduate lectures (157) and personal reading (127) as shown in figure 2. None of the respondents correctly identified all the components. Table 2 shows the most correctly identified blood com- ponents were fresh frozen plasma (94\%), platelet concentrate $(90.9 \%)$ and sedimented red cells $(86.8 \%)$. Table 2 also identifies fresh whole blood $(75.1 \%)$ as the most wrongly identified answer from the respondents. A greater number of the participants indicated that voluntary donation is the best source of blood donation. As shown in table 3. The most commonly identified 
benefits of BCT were: prevention of volume overload 222(83.8\%); specific form of therapy 221 (83.4\%), and better patient management 207 (78.1\%). Only $97(36.6 \%)$ of respondents identified BCT as cost effec- tive where few donors are available as shown in table 4. A high proportion of the respondents $(92.8 \%)$ would rather prescribe whole blood. One of the highlighted reasons was the ready availability of whole blood at the blood bank.

Table 2: Blood Components that can be transfused

\begin{tabular}{lll}
\hline Components & Frequency & Percentage* \\
\hline Sedimented red cells & 230 & $86.8 \%$ \\
Fresh whole blood & 199 & $75.1 \%$ \\
Platelet concentrate & 241 & $90.9 \%$ \\
Fresh frozen plasma & 249 & $94.0 \%$ \\
Cryoprecipitate & 206 & $77.7 \%$ \\
Plasma expanders & 65 & $24.5 \%$ \\
All of the Above & 15 & $5.7 \%$ \\
\hline
\end{tabular}

Table 3: Best source of donor

\begin{tabular}{|l|l|l|}
\hline Best Source of Donor & Frequency & Percent \\
\hline Voluntary & 197 & $74.2 \%$ \\
\hline Self-donor & 49 & $18.6 \%$ \\
\hline Remunerated donor & 3 & $1.0 \%$ \\
\hline Replacement donor & 6 & $2.1 \%$ \\
\hline Other & 10 & $4.1 \%$ \\
\hline Total & $\mathbf{2 6 5}$ & $\mathbf{1 0 0 . 0} \%$ \\
\hline
\end{tabular}

Table 4: Benefits of BCT

\begin{tabular}{|l|l|l|}
\hline Benefits of Blood Component Therapy & Frequency & Percent* \\
\hline Prevents volume overload & 222 & $83.8 \%$ \\
\hline It is a more modern form of therapy & 165 & $62.3 \%$ \\
\hline Prevents the formation of alloantibodies & 110 & $41.5 \%$ \\
\hline It is a more specific form of therapy & 221 & $83.4 \%$ \\
\hline Gives room for better management of our patients & 207 & $78.1 \%$ \\
\hline To correct hypovolemia. & 52 & $19.6 \%$ \\
\hline $\begin{array}{l}\text { Cost effectiveness for where few donors are } \\
\text { available. }\end{array}$ & 97 & $36.6 \%$ \\
\hline
\end{tabular}




\section{Practice of BCT}

More than half of the respondents indicated that they had prescribed BCT for the treatment of their patients. Sedimented cells 129(48.7\%), platelet concentrate $105(39.6 \%)$ and fresh frozen plasma $97(36.6 \%)$ were the most frequently prescribed blood components. The major indications were severe anaemia 201(75.8\%) and thrombocytopenia $153(57.7 \%)$ respectively. Some of the limitations to component therapy mentioned to the practice of BCT included; non-availability of components at the blood bank (78.5\%) and cost implications $(62.6 \%)$.

Majority of the physicians admitted difficulty in getting donors and some of the reasons highlighted were blood incompatibility for available donors and unwilligness of family members to donate as shown in table 5 .

Table 5: Limitations of the use of $\mathrm{BCT}$

\begin{tabular}{lll}
\hline Limitations to the use of BCT & Frequency & Percent \\
\hline Cost implication & 166 & $62.6 \%$ \\
Awareness not enough & 155 & $58.5 \%$ \\
Non availability in the blood bank & 208 & $78.5 \%$ \\
Non availability of component preparation materials & 131 & $49.4 \%$ \\
Component machine breakdown & 78 & $29.4 \%$
\end{tabular}

Table 6: Difficulties encountered in getting blood donors

\begin{tabular}{|l|l|l|}
\hline Difficulties in getting donors & Frequency & Percent* \\
\hline Donor available was blood-group incompatible & 158 & $59.6 \%$ \\
\hline $\begin{array}{l}\text { Donor available had transfusion transmissible } \\
\text { disease }\end{array}$ & 107 & $40.4 \%$ \\
\hline Inadequate PCV of donor & 119 & $44.9 \%$ \\
\hline Inadequate platelet count of donor & 31 & $11.7 \%$ \\
\hline No family member around to donate & 151 & $57.0 \%$ \\
\hline Family member available unwilling to screen & 133 & $50.2 \%$ \\
\hline Cost of paying a donor & 116 & $43.8 \%$ \\
\hline No voluntary donor & 144 & $54.3 \%$ \\
\hline
\end{tabular}






\section{Discussion}

One of the key points determining the efficiency of any blood transfusion service is the knowledge level of the physicians using the service.

This study showed that major information on blood component therapy was from undergraduate training. With the changing growing global trends in transfusion medicine, basic knowledge from undergraduate studies may not be sufficient to ensure standard medical practice.

Most of the physicians were able to correctly identify the different types of blood components. However, fresh whole blood was wrongly identified as a blood component by 199 participants. Fresh whole blood has been variously defined as blood collected at less than 4 hours (ultra-fresh), 24 hours, 72 hours and stored at room temperature?. Its ushas been advocated in cardiac surgery,burns and ,massive transfusion, particularly in the military setting ${ }^{10,11}$. Potential risks have been reported with the use of fresh whole blood therefore, its use is best limited to clinical trials and situations where there is life-threatening bleeding, and blood component therapy is unavailable ${ }^{12}$. Physicians should know the different types of blood components and their doses to be able to make appropriate prescriptions.

BCT has been reported to be beneficial in protecting the national inventory at times of national blood shortage $^{13}$. This is because several patients can potentially benefit from components derived from one unit of donated blood. This is contrary to the findings in this study where less of the physicians believe that BCT is cost effective where few donors are available.

Majority of the physicians prefer to prescribe whole blood despite showing a good knowledge of the benefits of BCT. This is in congruence with of findings in the literature which showed most transfusion recipients receive whole blood ${ }^{14,15}$. The physicians' preference to whole blood is probably because of 'availability' reasons. Non-availability of the components was identified as one of the limitations to the practice of BCT as reported in most studies ${ }^{16,17}$. Sedimented cells was the most prescribed blood component as seen in other studies ${ }^{17}$.

The study also shows that most physicians agree that voluntary blood donation still remains the best source of blood donation. However, there is paucity of voluntary donors in most developing countries including Nigeria as seen in our study where more than half of the doctors identified the absence of voluntary dona- tion as one of the difficulties encountered in blood donation $^{18,19}$.

Replacement/family donors is reported to be the the most prevalent source of blood donation ${ }^{20}$. This finding has been linked to the fact that it may actually cost less to procure and is also well adapted to the extended family support system of many Nigerian and African communities $^{20}$. Some of the limitations to this practice as also observed in this study includes blood group incompatibility or refusal to donate by the family donors.

\section{Limitations of study}

The generalizability of this study may be limited since study participants consisted of physicians from two tertiary hospitals.

\section{Conclusion}

Our study has shown that majority of the physicians in Nigeria have a good knowledge regarding blood component therapy. However, availability of the different components limits optimal practice of blood component therapy.

\section{Authorship contribution}

EIO conceptualised the work and contributed significantly to writing the discussion. CD contributed to the acquisition and analysis of data for the work. HO contributed to literature review ad review of the manuscript.

\section{COonflict of interest}

None declared.

\section{References}

1. Component therapy http://medical-dictionary.thefreedictionary.com/component+therapy (cited 30th March, 2017)

http:/ / medical-dictionary.thefreedictionary.com/ blood+component + therapy

2. European Directorate for the Quality of Medicines \& Healthcare. Guide to the Preparation, Use and Quality Assurance of Blood Components: Recommendation Number R (95) 15.18ed. Strasbourg: EDQM of the Council of Europe; 2015. p. 85-95.

3. Sawadogo S, Nébié K, Kafando E, Millogo T, Ouattara S, Dahourou H, Ouédraogo G, Nana S, Deneys V. Preparation of red cell concentrates in low-income countries: Efficacy of whole blood settling method by simple gravity in Burkina Faso. Int J Blood Transfus Immunohematol 2016;6:20-29.

4. Karp J.K., Weston, C.M. \& King, K.E. (2011) Trans- 
fusion medicine in American undergraduate medical education. Transfusion, 51, 2470- 2479.

5. O'Brien KL, Champeaux AL, Sundell ZE, Short MW, Roth BJ. Transfusion medicine knowledge in postgraduate year 1 residents. Transfusion. 2010;50:1649-1653. doi: 10.1111/j.1537-2995.2010.02628.x.

6. Philip J, Kumar S, Chatterjee T, Mallhi RS. Knowledge of Transfusion Medicine Among Resident Doctors in Clinical Specialities: A Cross-Sectional Study from a Tertiary Care Centre. Indian J Hematol Blood Transfus. 2015;31(3):374-377. doi:10.1007/s12288-014-0470-5.

7. Kowsalya V, Vijayakumar R, Chidarmbaram R, Srikumar R. A study on Knowledge, Attitude and Practice Regarding Volountary Blood Donation among Medical students in Puducherry India. Pakistan Journal of Biological Sciences 2013; 16(9): 439-442.

8. Benedict N, Aigberadion U, Nwannadi IA, Aigbe I. Knowledge, attitude and practice of voluntary blood donation among physicians in a tertiary health facility of a developing country. International Journal of Blood Transfusion and Immunohematology, 2012; 2(2): 4-10.

9. Spinella PC (2008). Warm fresh whole blood transfusion for severe hemorrhage: U.S. military and potential civilian applications. Critical Care Medicine 36(7 Suppl):S340-345. http://www.ncbi.nlm.nih.gov/pubmed/18594261

(Accessed December 2019).

10. Repine TB, Perkins JG, Kauvar DS and Blackborne $\mathrm{L}$ (2006). The use of fresh whole blood in massive transfusion. Journal of Trauma 60(6 Suppl):S59-69. http://www.ncbi.nlm.nih.gov/pubmed/16763483

11. Valleley MS, Buckley KW, Hayes KM, Fortuna RR, Geiss DM, Holt DW. Are there benefits to a fresh whole blood vs. packed red blood cell cardiopulmonary bypass prime on outcomes in neonatal and pediatric cardiac surgery?. J Extra Corpor Technol. 2007;39(3):168-176.
12. Patient Blood Management Guidelines: Module 1.Critical bleeding massive transfusion. https:// www.blood.gov.au/pubs/pbm/module1/background/3.6.2.html. (assessed December 2019).

13. Erhabor O, Adias TC. From whole blood to component therapy: the economic, supply/demand need for implementation of component therapy in sub-Saharan Africa. Transfus Clin Biol. 2011 Dec;18(5-6):516-26. 14. Aliyu I, Michael G, Ibrahim H, Ibrahim ZF, Aliyu G, Isaiah AT. Blood transfusion request pattern in a medical Centre in northwestern Nigeria. Glob J Transfus Med. 2017;2(1):52-5.

15. Okoroiwu, H.U., Okafor, I.M. Demographic characteristics of blood and blood components transfusion recipients and pattern of blood utilization in a tertiary health institution in southern Nigeria. BMC Hematol 18, 16 (2018) doi:10.1186/s12878-018-0112-5.

16. Towards $100 \%$ voluntary blood donation in Nigeria. https://guardian.ng/features/towards-100-voluntary-blood-donation-in-nigeria/ (accessed $09^{\text {th }}$ January,2020.

17. Arewa OP. One year clinical audit of the use of blood and blood components at a tertiary hospital in Nigeria. Nigerian Journal of Clinical Practice 2009; 12(4):429-433

18. Ugwu A O, Madu A J, Efobi C C, Ibegbulam O G. Pattern of blood donation and characteristics of blood donors in Enugu, Southeast Nigeria. Niger J Clin Pract 2018;21:1438-43 PubMed

19. Okocha C, Ogbenna AA, Ezeama N, Aneke J, Ezeh T. Pattern of blood procurement and utilization in a university hospital in Southeast Nigeria. Ann Trop Pathol 2019;10:63-7 PubMed

20. Aneke JC, Okocha CE. Blood transfusion safety; current status and challenges in Nigeria. Asian J Transfus Sci. 2017;11(1):1-5. doi:10.4103/0973-6247.200781. 